\title{
ANALYSIS OF DOOR-TYPE MODULAR STEEL SCAFFOLDS BASED ON A NOVEL NUMERICAL METHOD
}

\author{
Zhongwei Zhao ${ }^{1}$ and Zhihua Chen ${ }^{1,2, *}$ \\ ${ }^{1}$ Department of Civil Engineering, Tianjin University, Tianjin, 300072, China \\ ${ }^{2}$ State Key Laboratory of Hydraulic Engineering Simulation and Safety, Tianjin University, Tianjin 300072,China \\ *(Corresponding author: E-mail: zhchen@tju.edu.cn)
}

Received: 21 August 2015; Revised: 28 August 2015; Accepted: 4 October 2015

\begin{abstract}
As supporting scaffolds, door-type modular steel scaffolds steel scaffolds are commonly used in construction. They were repeatedly used in practical project. Member imperfection often occurs when scaffolds were used repeatedly. Influence of member imperfection and joint stiffness on ultimate load of door-type modular steel scaffolds was systematically investigated in this paper. A novel numerical method was adopted and it can be conveniently used based on general finite element software. The method can be adopted for all kinds of scaffold systems. Reliability of the method was validated firstly. Then influence of splice joint stiffness and screw jack stiffness on ultimate load capacity was investigated. Influence of member imperfection was investigated in the end.
\end{abstract}

Keywords: Double element method, member imperfection, door-type scaffold, buckling behavior, semi-rigid joints

DOI:10.18057/IJASC.2016.12.3.6

\section{INTRODUCTION}

Modular steel scaffolds are temporary structures and they are commonly used as supporting scaffolds to support buildings under construction or constructors in construction site. As a kind of temporary structures, reliability of modular steel scaffolds has not been brought to the forefront. Many accidents caused by scaffold collapse happened all over the world.

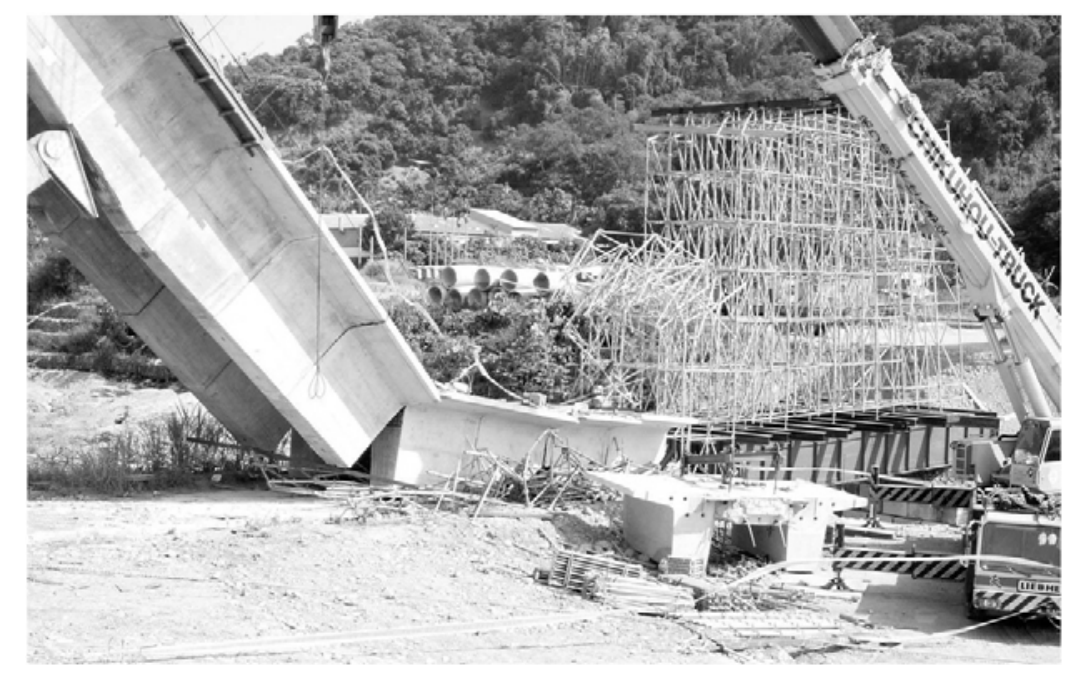

Figure 1. Scaffold Collapse Occurred at a Construction Site in Taichung, Taiwan [1]

$\mathrm{Yu}$ investigated the influence of boundary conditions on instability of multi-storey door-type modular steel scaffolds[2]. In this investigation the boundary condition was idealized as pinned or fixed condition. But in most cases, the door-type modular steel scaffolds were semi-rigidly restrained or connected. Chu et al.[3] studied single storey double bay scaffolds. In the presence of 
restraints on the loading beam and the jack bases, the top and base were modelled with various boundary conditions, and the scaffold connections were assumed to be rigid [4]. But scaffold joints are complex in nature due to the need for rapid assembly and reassembly in construction. The cuplok connections behave as semi-rigid joints, and show looseness with small rotational stiffness at the beginning of loading. Once the joints lock into place under applied load, the joints become stiffer[5].

So many studies have been conducted to investigate mechanical of scaffold both by experimental test and numerical test [6]. In terms of analytical study on steel scaffolds, Zhang and Rasmussen et al.[9] analyzed the variability of parameters related to steel scaffolds, including joint stiffness, initial geometric imperfection, yield stress, and load eccentricity. That study also obtained the structural strength of the steel scaffolding structures based on Monte Carlo simulation. Zhang and Rasmussen et al.[10] also investigated the failure modes of steel scaffolds, the effect of different random variables on structural strength and the reliability analysis of scaffolding structures. Chan et al.[11] conducted nonlinear analyses on the shoring structures that did not assume an effective length. Based on stability functions, while adopting the notional disturbance force and considering the P- $\delta$ and P- $\Delta$ effects, the analytical method accurately estimates the load-carrying capacities of scaffolding structures with nonlinear analyses.

By means of available commercial finite element software such as ANSYS [12] 13] and NIDA [14], recent studies on scaffold behavior have been carried out using tANhree-dimensional models such as those presented by Prabhakaran et al. [15], Milojkovic et al.[16], and Godley and Beale[17].

Eigenvalue (buckling) analysis of the structural model was often conducted and the lowest eigen mode was taken to create an initially imperfect structural frame for the second-order structural analysis. For scaffold systems, these same approaches can be applied to model the effects of initial imperfections in the analysis. For example, Yu et al.[2] and Chu et al. [18] integrated lowest eigen mode with the magnitude of the column out-of-straightness of 0.001 of the height of the scaffold units into the model. This method is simple and convent, but it neglects the nature of initial imperfection: randomness. The ultimate load obtained by this method may be too conservative.

The height of scaffolds used in large-span structures is often large, for example the scaffold system used in YUJIAPU railway station, shown as in Figure 2. In this case, the joint stiffness and member imperfection may influence its ultimate load in a certain degree.

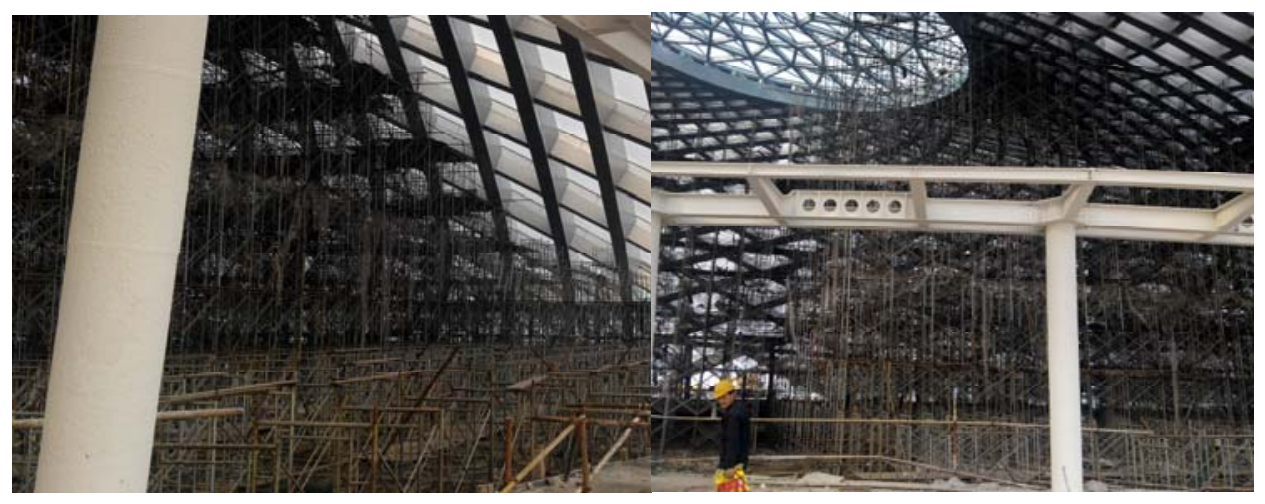

Figure 2. Door-type Modular Steel Ascaffold at YUJIAPU 


\section{IMPERFECT COMPONENTS WITH DOUBLE ELEMENT}

\subsection{Establishment of Imperfect components}

General finite element software ANSYS [12, 13] was also employed to establish imperfect elements. In traditional analysis, straight line was generated and meshed to simulate components of latticed shell. The member imperfection cannot be considered in this case. In this research, straight line was replaced by curved line through 'BSPLIN' command. In the middle location of the component, magnitude of imperfection was set. In most analysis, the imperfection is assumed to be of a half-wave sinusoid. This can be achieved by adding imperfection value at other points to make the b-spline close to half-wave sinusoid, as shown in Figure 3. To set the imperfection value conveniently, local coordinate system was created. The $\mathrm{x}$ axis is in member direction, $\mathrm{y}$ axis is in vertical direction. Imperfection value can be generated by adopting sine function in ANSYS [12, 13]. All of the imperfect member can be generated through looping statements. The whole process can be performed easily and it is easy for engineers to master.

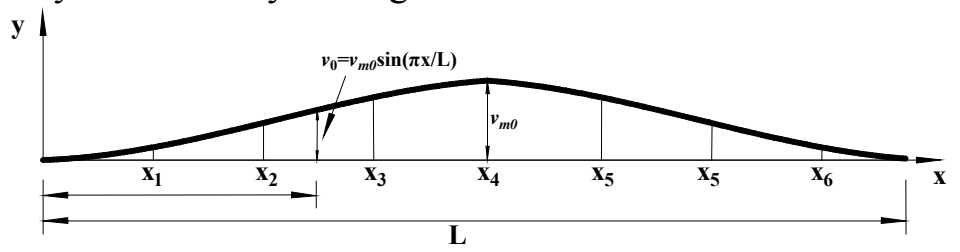

Figure 3. Imperfection Member and Local Coordinate System

\subsection{Components with Double Element}

Research on the stiffness of joints and their effects on the behavior of structures has been an area of interest to engineers and scientists in recent years and many applicable conclusions have been achieved. But until now, there has been no applicable method to consider joint stiffness in general finite element software. A simplified method considering joint stiffness was proposed in this paper.

This method assumed that joints of latticed shell were composed by two elements: Beam element with only bending stiffness and beam element without bending and torsional stiffness which act as a link element, shown as in

Figure 4 .

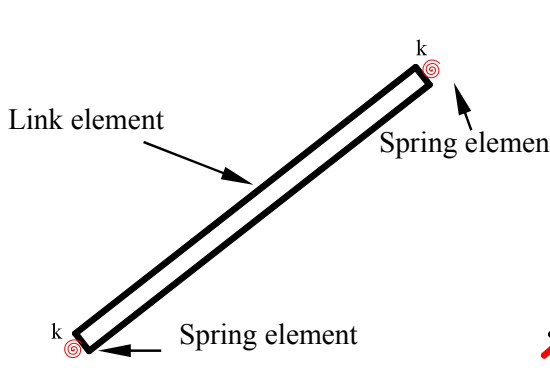

a) Beam-spring element

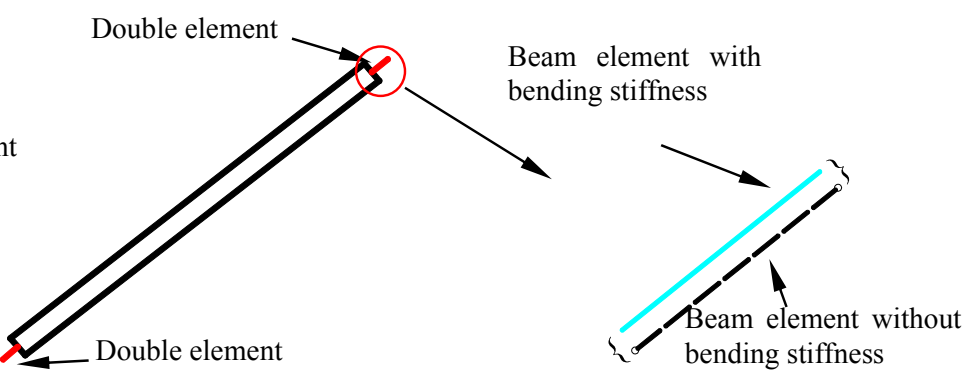

b) Component with double element

Figure 4. Numerical Model Considering Joints Stiffness 
Assuming that the joint stiffness is $k$ and the length of joint domain is $l$. Then the joint was replaced by double element and its length was set equal to the joint dimension. The rotation angle of joint and double element under action of moment $M$ should be the same.

Rotation angle of the beam under action of moment $M$, shown as in Figure 5, can be calculated through Eq. 1 for the beam with a constant cross section. Then the bending stiffness of the beam can be represented by Eq. 2 .

Let the bending stiffness of double element equal to joint stiffness $k$, then Eq. 3. can be derived.

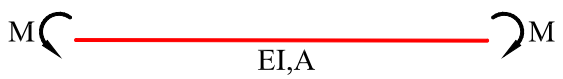

Figure 5. Beam under Action of Moment
$\theta=\int_{l} \frac{M}{E I} d l=\frac{M l}{E I}$
(1)
$\frac{M}{\theta}=\frac{E I}{l}$
(2)
$I=\frac{k l}{E}$

(3)

Investigations presented in this paper was conducted based on general finite element software ANSYS [12, 13]. BEAM4 element in ANSYS [12, 13] is a uniaxial element with tension, compression, torsion, and bending capabilities. The element has six degrees of freedom at each node: translations in the nodal $\mathrm{x}, \mathrm{y}$, and $\mathrm{z}$ directions and rotations about the nodal $\mathrm{x}, \mathrm{y}$, and $\mathrm{z}$ axes. The equilibrium equation and stiffness matrix of BEAM4 in element coordinates is shown as in Eq. 4 [13].

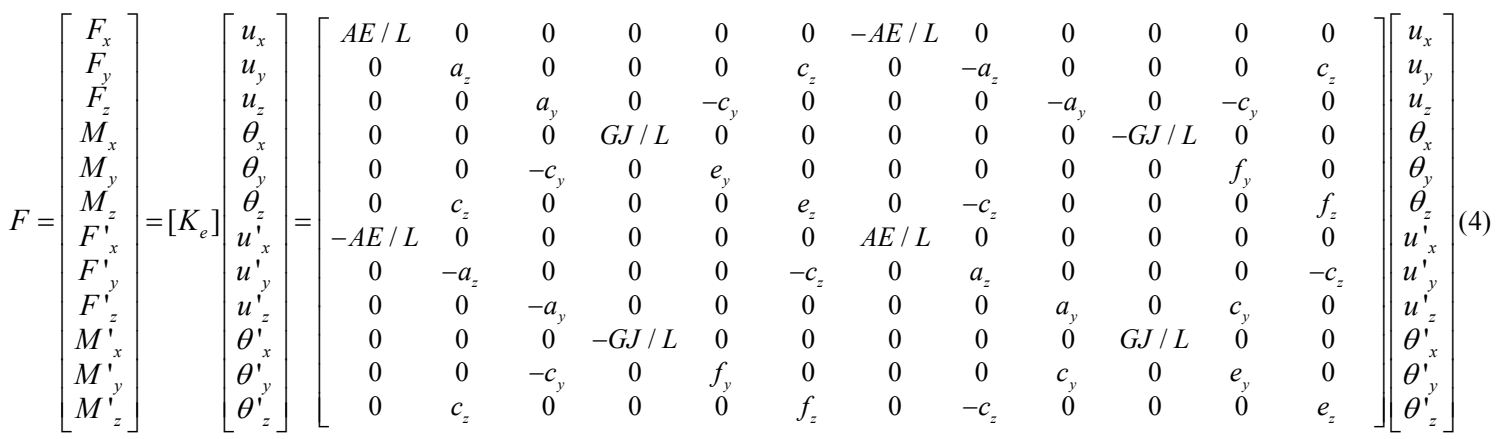

Where $A, E, L, G$ and $J$ are cross-section area, Young's modulus, element length, shear modulus and torsional moment of inertia.

$a_{y(z)}=\frac{12 E I_{y(z)}}{L^{3}\left(1+\phi_{z(y)}\right)}, \quad c_{y(z)}=\frac{6 E I_{y(z)}}{L^{2}\left(1+\phi_{z(y)}\right)}, \quad e_{y(z)}=\frac{\left(4+\phi_{z(y)}\right) E I_{y(z)}}{L\left(1+\phi_{z(y)}\right)}, \quad \phi_{z(y)}=\frac{12 E I_{y(z)}}{G A_{y(z)}^{s} L^{2}}$

$I_{i}$ is moment of inertia about direction $i, A_{y(z)}^{s}$ is shear area normal to direction $\mathrm{y}(\mathrm{z})$ axes.

For beam element with bending stiffness in double-element, only the bending stiffness was assigned by real constant. The equilibrium equation and stiffness matrix of this element in element coordinates is shown as in Eq.5. For Beam element without bending stiffness in double-element, it was also BEAM4 element in ANSYS $[12,13]$, but the bending stiffness was set a very little value, that the beam element can be assumed as a link element. The equilibrium equation and stiffness matrix of this element in element coordinates is shown as in Eq. 6. 


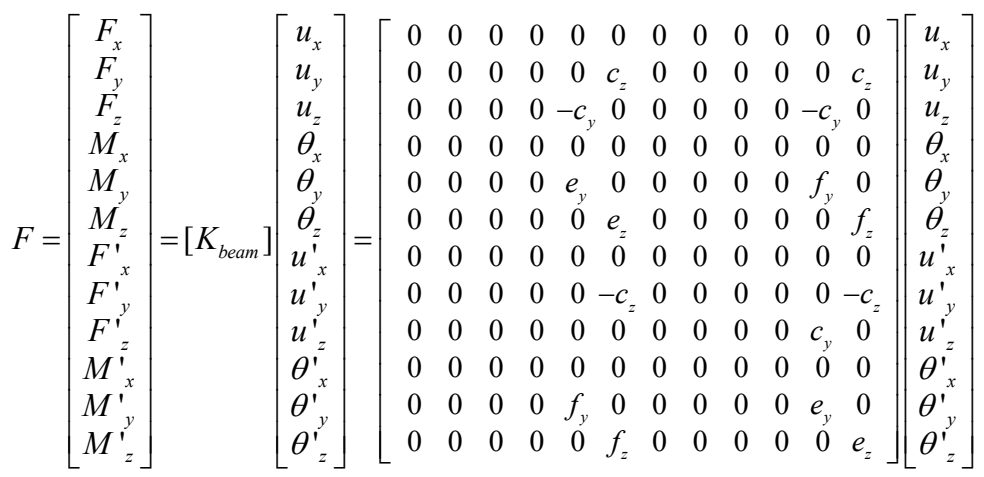

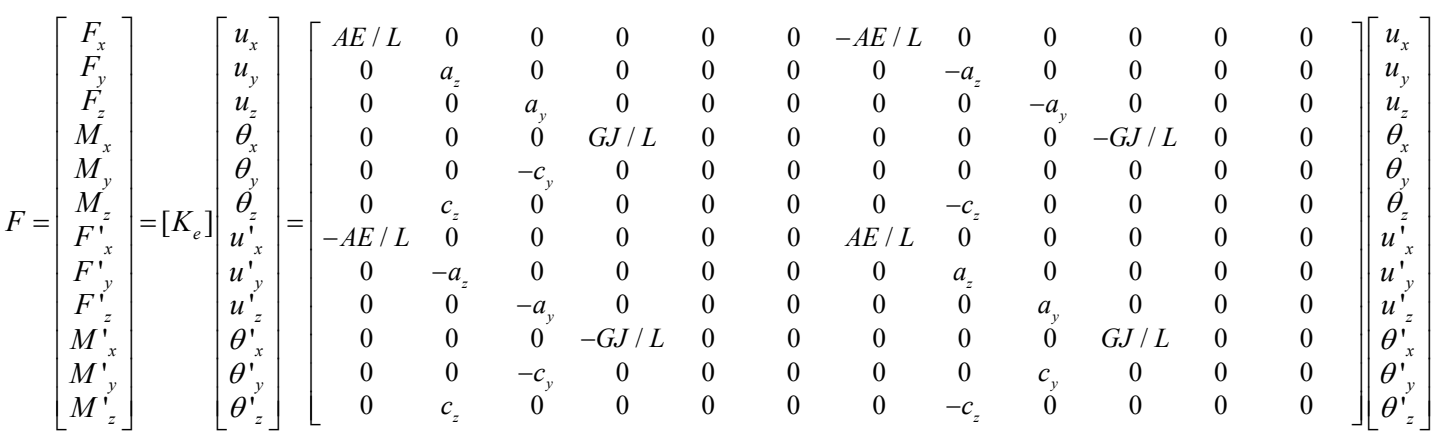

\section{ESTABLISHMENT OF NUMERICAL MODEL}

Analysis was conducted based on work specimens tested by $\mathrm{Yu}$ et al. [2]. The member configurations of the door-type modular steel scaffolds together with their dimensions were illustrated as in

Figure 6 .

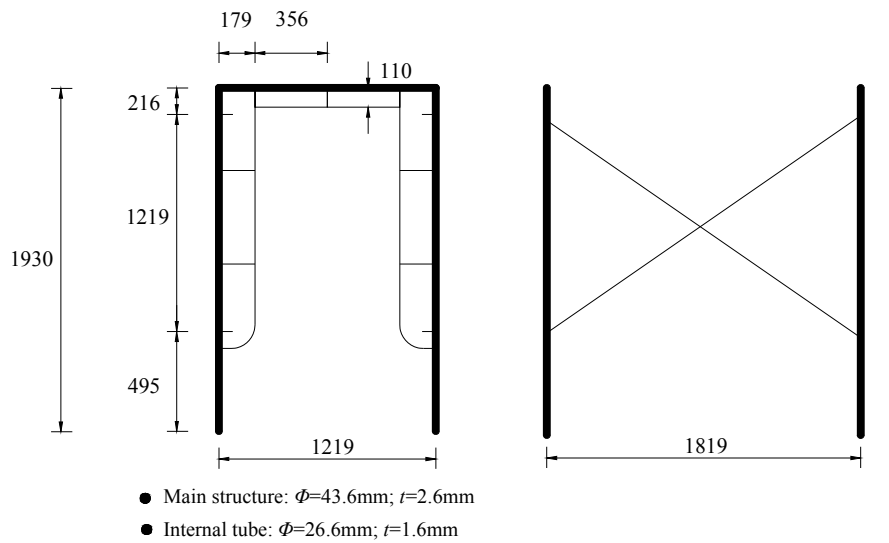

Figure 6. Typical Dimensions of Scaffolding Frame (unite: $\mathrm{mm}$ )

Beam188 element was adopted to establish finite element models of scaffold system. To model the mechanical behavior of $\mathrm{x}$-brace, translational degrees of freedom of nodes located at middle of the two brace were coupled together. The bending degrees of node at two ends of brace were released by "ENDRELEASE" command. Double element was established to model connection between different modular scaffolds and the screw jack at bottom of scaffold. 


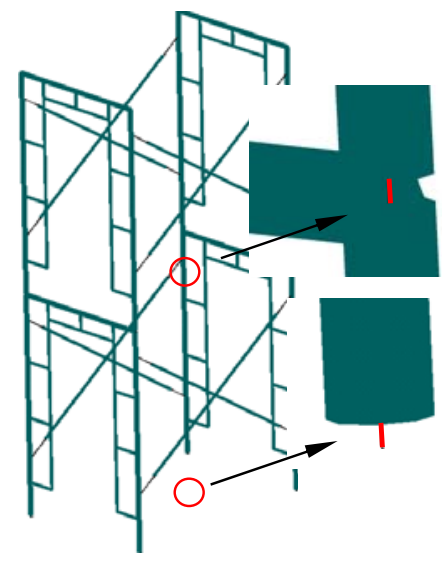

Figure 7. Finite Element Models of Two-storey Scaffold System

\section{RESULTS AND DISCUSSIONS}

\subsection{Validation of Numerical Method}

To validated the reliability of numerical method presented in this paper, two-storey scaffold system was analyzed. The boundary conditions with various degrees of positional and rotational restraints are classified into four categories.

- Pinned-Fixed condition,

- Pinned-Pinned condition,

- Free-Fixed condition, and

- Free-Pinned condition,

where the first condition refers to the positional restraint provided at the top of the scaffold while the second refers to the rotational restraint provided at the bottom of the scaffold, respectively.

The results derived was shown as in Figure 8 and it was compared to that derived by Yu et al.[2], shown as in Figure 9. It can be concluded that the boundary conditions of door-type scaffold system have great influence on its ultimate load capacity. The reliability of numerical model established based on method proposed in this paper was validated through comparison shown in Figure 9. It can be seen that the results were highly consistent with each other.

Figure 10 shows failure modes of two-storey scaffold system with different boundary conditions. It can be concluded that the boundary condition will also determine the failure modes.

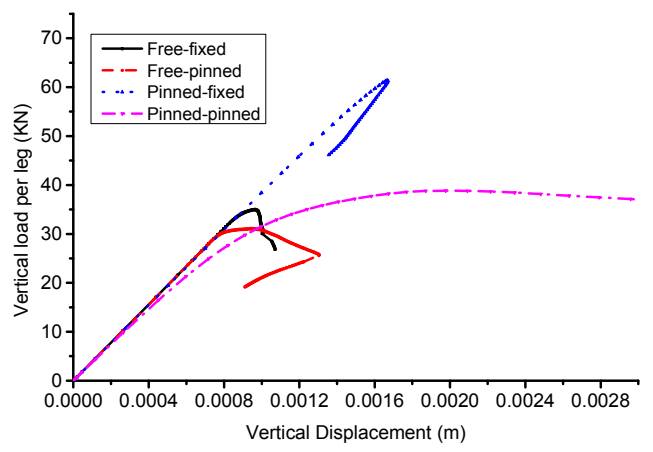

Figure 8. Load Deformation Curves of Modular Steel Scaffolds.

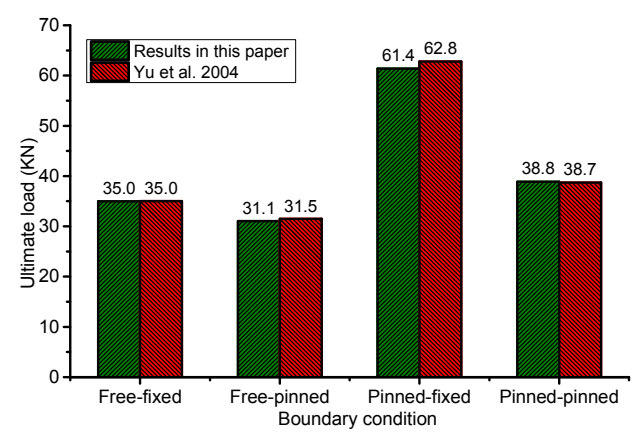

Figure 9. Ultimate Load of Modular Steel Scaffolds. 


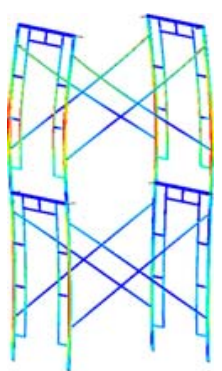

a) Free-pinned

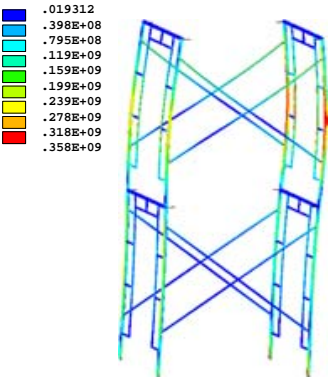

b) Free-fixed

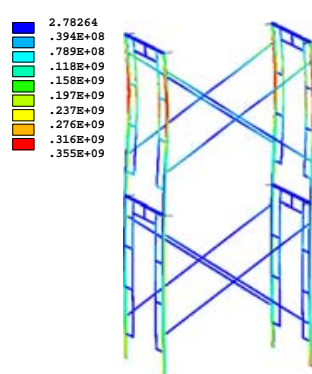

c) Pinned-fixed

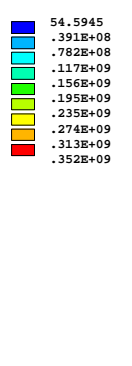

\section{ed}

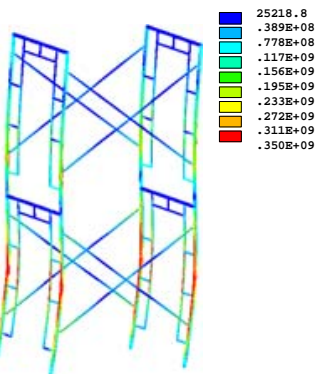

d) Pinned- Pinned

Figure 10. Failure Mode of Two-story, One-bay Scaffold System

\subsection{Influence of Splice Stiffness}

\subsubsection{Free-fixed Condition}

To investigate the influence of splice stiffness on ultimate load capacity of door-type scaffolds system, double element between different modular steel scaffolds were given different stiffness factor $k$ to simulate influence of splice stiffness. Where $k$ indicates ratio of splice stiffness to bending stiffness of stand column. The boundary was free-fixed condition.

The load-displacement curves with different splice stiffness were shown as in Figure 11. It can be concluded from the results that the splice stiffness has almost no influence on its ultimate load capacity. The influence is so slight that can be neglected. The splice stiffness will affect mechanical behavior of three-story, one-bay scaffold system after failure and will not for the three-story, two-bay scaffold system. The splice stiffness will also not influence initial structural stiffness.

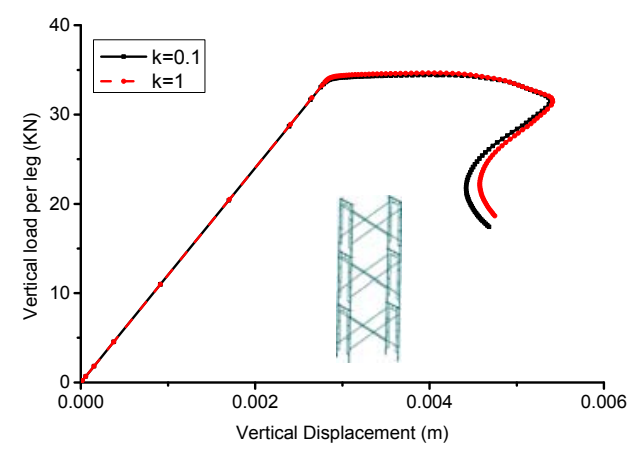

a) Three-story, one-bay scaffold system

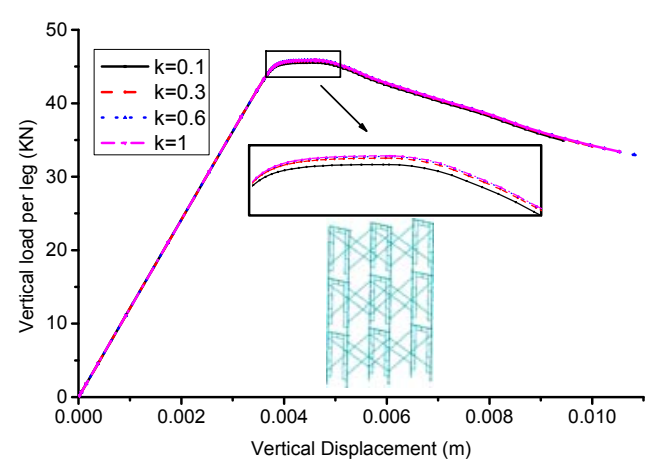

b) Three-story, two-bay scaffold system

Figure 11. Influence of Splice Stiffness on Ultimate Load Capacity

Failure modes of three-story, two-bay scaffold system were shown as in Figure 12. It can be concluded that the splice stiffness will not influence failure mode. Failure was caused by bucking of stand column of the topmost storey. This may be caused by free condition of top nodes. 


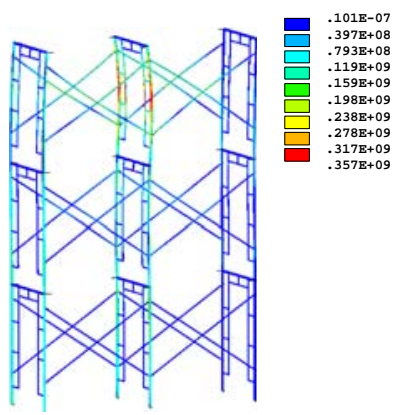

a) $k=0.1$

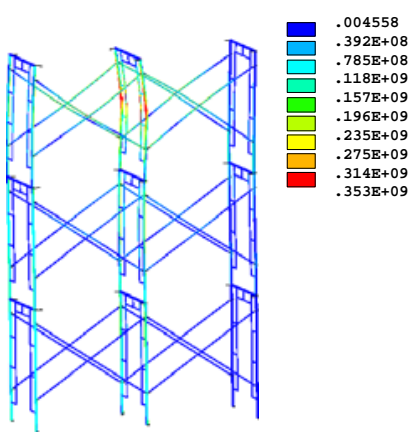

b) $k=1$

Figure 12. Failure Mode of Three-story, Two-bay Scaffold System

\subsubsection{Pinned-fixed Condition}

Analysis was conducted to investigate influence of splice stiffness on scaffold system with top nodes pinned constraint. Three-story, one-bay and three-story, four-bay scaffold system were analyzed. Load-displacement curves were shown as in Figure 13.

It can be seen from Figure 13 that the ultimate load was reduced from $92 \mathrm{KN}$ to $87.4 \mathrm{KN}$ when splice joint stiffness factor was set as 1 and 0.1 respectively for the three-story, one-bay scaffold system. For three-story, four-bay scaffold system, the ultimate load was reduced from 94KN to $90.26 \mathrm{KN}$. It can be concluded that influence of splice stiffness on pinned-fixed condition is larger than that of free-fixed condition. This is caused by failure modes. The ultimate load was reduced by $5 \%$ and $4 \%$ for the two analyzed scaffold system.

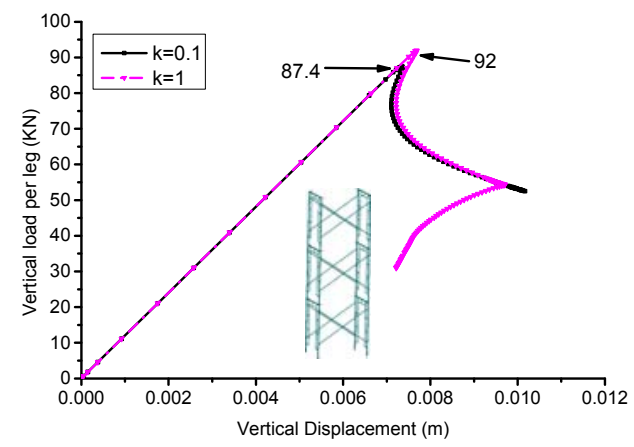

a) Three-story, one-bay scaffold system

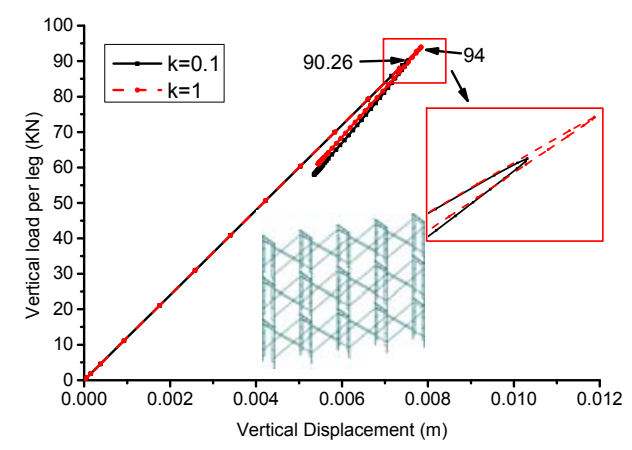

b) Three-story, four-bay scaffold system

Figure 13. Influence of Splice Stiffness on Ultimate Load Capacity

\subsection{Influence of Screw Jack Stiffness}

\subsubsection{Free-fixed condition}

According to investigations conducted by $\mathrm{Yu}$ [2] that screw jack stiffness on ultimate load capacity of one-storey scaffold is the greatest. The ultimate load was reduced by $59 \%$ when the screw jack was changed from fixed condition to pinned condition. In this section, scaffold system that is in free-fixed condition was analyzed and the results were shown as in Figure 14. It can be concluded from Figure 14. a) that the reduced factor was $88.7 \%$ for two-storey scaffold system and it can also be concluded from Figure $14 \mathrm{~b}$ ) that the screw jack stiffness almost has no influence on ultimate load for three-storey scaffold system. This is in consistent with the conclusions derived by Yu et al. [2]. 
It can be deduced from the results mention above that the screw jack stiffness has influence on one-storey and two-storey scaffold system. The screw jack stiffness will has no influence on ultimate load capacity when the scaffold system is more than two stories.

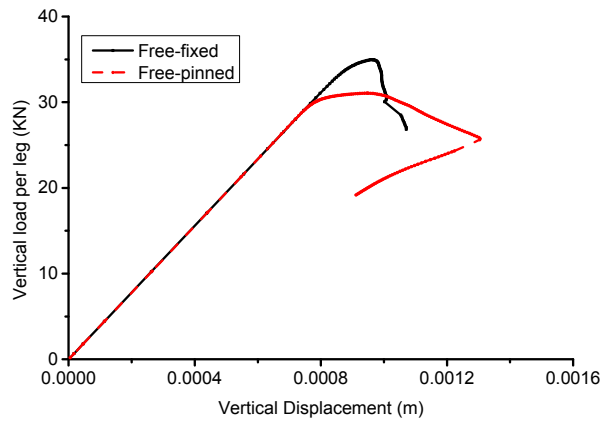

a) Two-story, one-bay scaffold system

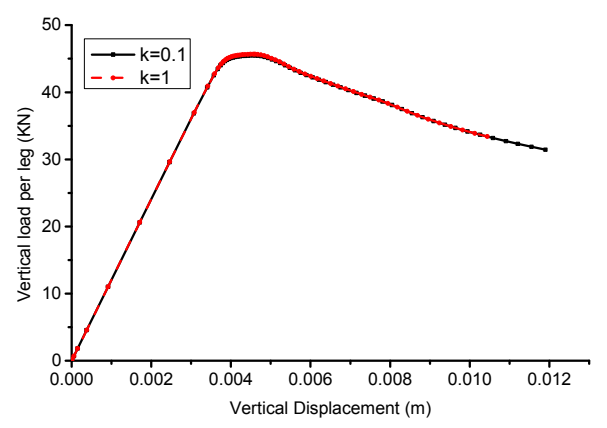

b) Three-story, one-bay scaffold system

Figure 14. Influence of Screw Jack Stiffness (free-fixed)

\subsubsection{Pinned-fixed condition}

To investigate influence of screw jack stiffness on the scaffold systems in pinned-fixed condition. Analysis were conducted and the results were shown as in Figure 15. It can be concluded that the screw jack stiffness has little influence on ultimate load if the scaffold system was pinned-fixed constraint and more two stories.

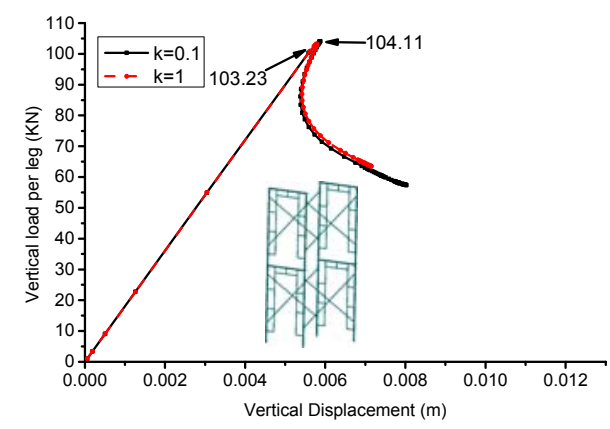

a) Two-story, one-bay scaffold system

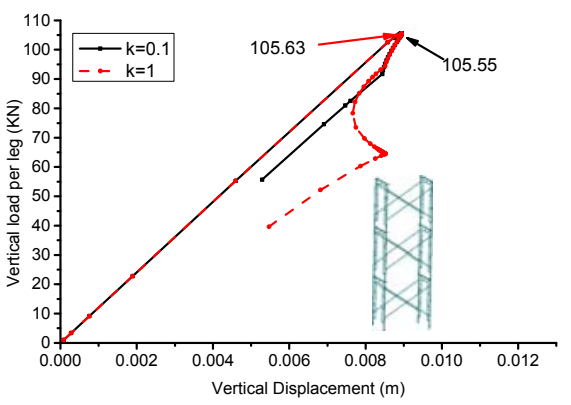

b) Three-story, one-bay scaffold system

Figure 15. Influence of Screw Jack Stiffness (pinned-fixed)

\section{INFLUENCE OF INITIAL IMPERFECTION}

In practical project, it is inevitable that the scaffold systems have some initial imperfections, such as initial bending of member. The initial bending will decrease load capacity in a certain degree. So analysis was systematically conducted to investigate its influence. Different scaffold systems were analyzed and the results were shown as in Figure 16. $M 0$ and $h$ indicate magnitude of initial bending and height of scaffold modular.

Figure 16 shows results of different scaffold system. It can be concluded from the results that when the initial bending magnitude $M 0$ was less than $h / 1000$ which is the maximum allowable imperfection in [19], the influence of initial member bending has little influence on ultimate load capacity. The structural stiffness was also slightly influenced. So the maximum allowable member imperfection can also be determined as $h / 1000$. 


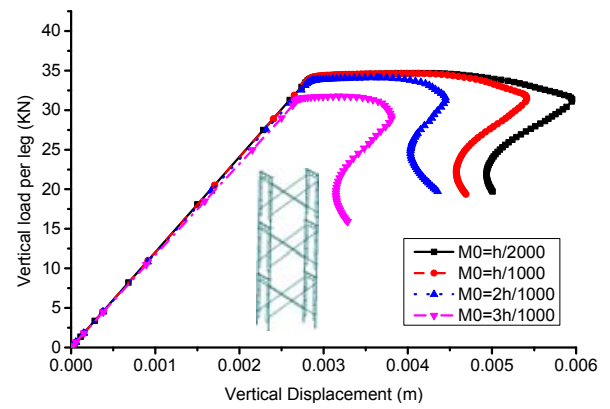

a) One-bay

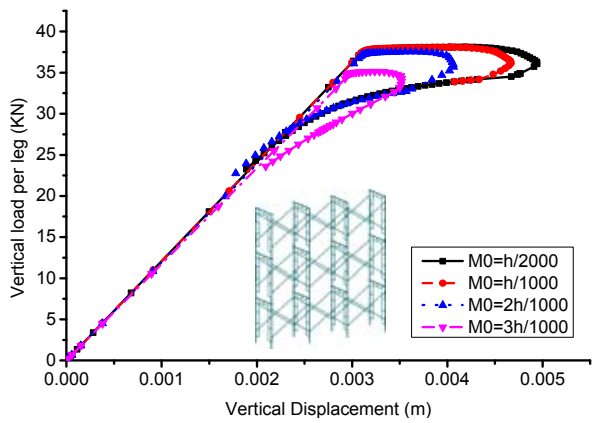

c) Three-bay

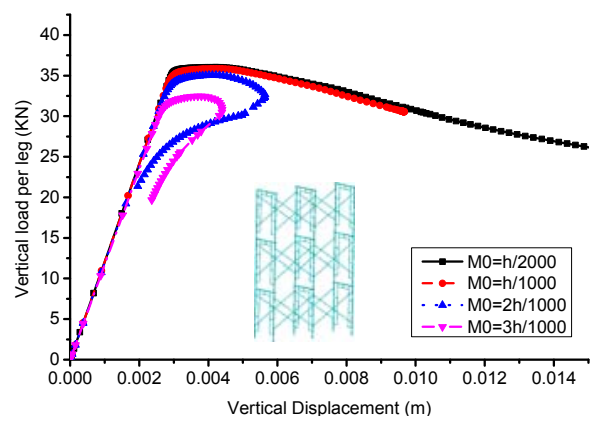

b) Two-bay

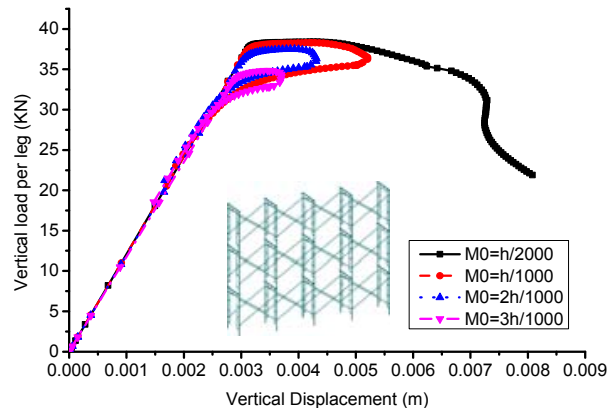

d) Four-bay

Figure 16. Influence of Initial Imperfection

Figure 17 shows failure modes of different scaffold systems with member imperfection. It can be concluded that failure occurs at the top storey. So it is easy to be understood that the screw jack stiffness almost has no influence on ultimate load when the scaffold system is more than two stories.

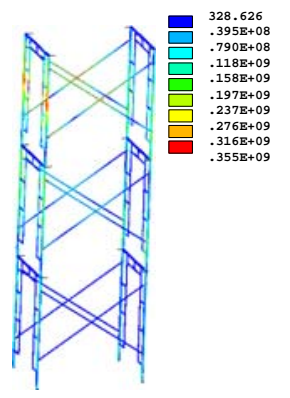

a) One-bay

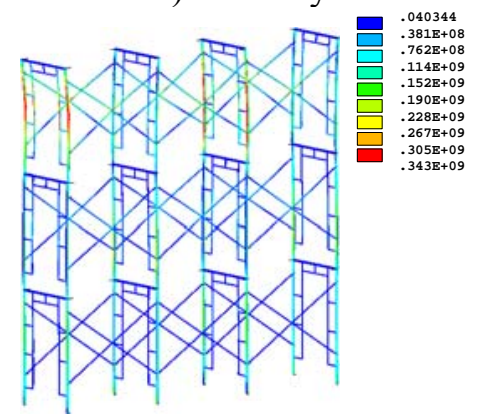

c) Three-bay

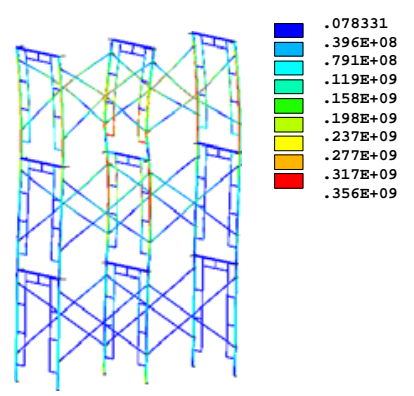

b) Two-bay

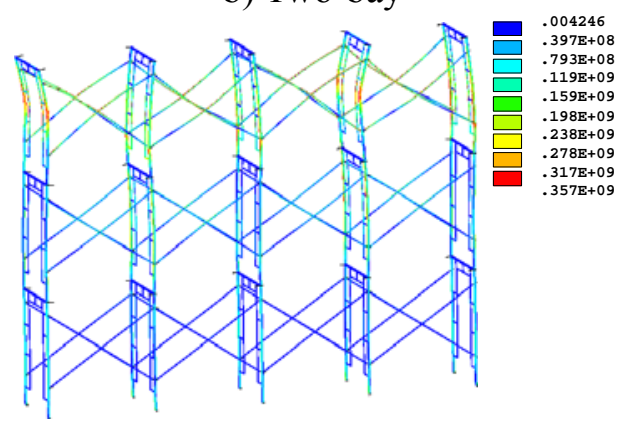

d) Four-bay

Figure 17. Failure Mode of Scaffold System 


\section{CONCLUSIONS}

A novel numerical method was proposed in this paper. It can be easily adopted in analysis of joint stiffness and member imperfection. Reliability of the method was validated firstly. The method can be adopted for all kinds of scaffold systems. Then influence of splice joint stiffness was analyzed. It was concluded that splice joint stiffness has little influence on ultimate load in free-fixed condition and the influence is larger in pinned-fixed condition. The screw jack stiffness has great influence on ultimate load of lower scaffold system and the influence can be neglected when the scaffold system is more than two stories.

\section{REFERENCES}

[1] Peng, J.L., Wu, C.W., Chan, S.L. and Huang, C.H., "Experimental and Numerical Studies of Practical System Scaffolds", Journal of Constructional Steel Research, 2013, Vol. 91, pp. 64-75.

[2] Yu, W.K., Chung, K.F. and Chan, S.L., "Structural Instability of Multi-storey Door-type Modular Steel Scaffolds", Engineering Structures, 2004, Vol. 26, No. 7, pp. 867-881.

[3] Chu, A.Y.T., Chan, S.L. and Chung, K.F., "Stability of Modular Steel Scaffolding Systems-theory and Verification", In: Proceedings of International Conference Advances in Building Technology", 2002, pp. 621-8.

[4] Tayakorn, Chandrangsu and Kim, J.R. Rasmussen, "Structural Modelling of Support Scaffold Systems", Journal of Constructional Steel Research, 2011, No. 67, No. 5, pp. 866-875.

[5] Godley, M.H.R. and Beale, R.G., "Sway Stiffness of Scaffold Structures", Structural Engineer, 1997, Vol. 75, pp. 4-12.

[6] Chan, S.L., Huang, H.Y. and Fang, L.X., "Advanced Analysis of Imperfect Portal Frames with Semi-rigid Base connections", Journal of Engineering Mechanics, 2005, Vol. 131, pp. 633-40.

[7] Weesner, L.B. and Jones, H.L., "Experimental and Analytical Capacity of Frame Scaffolding”, Engineering Structures, 2001, Vol. 23, pp. 592-9.

[8] Zhang, H., Chandrangsu, T. and Rasmussen, K.J.R., "Probabilistic Study of the Strength of Steel Scaffold Systems", Struct. Saf., 2010, Vol. 32, pp. 393-401.

[9] Zhang, H., Chandrangsu, T. and Rasmussen, K.J.R., "Probabilistic Study of the Strength of Steel Scaffold Systems”, Structural Safety, 2010, Vol. 32, pp. 393-401.

[10] Zhang, H., Rasmussen, K.J.R. and Ellingwood, B.R., "Reliability Assessment of Steel Scaffold Shoring Structure for Concrete Formwork", Engineering Structures, 2012, Vol. 36, pp. 81-89.

[11] Chan, S.L., Chu, A.Y.T. and Albermani, F.G., "Stability and Simulation-based Design of Steel Scaffolding without Using the Effective Length Method", Structural Stability and Dynamics, 2003, Vol. 3, No. 4, pp. 443-460.

[12] ANSYS. ANSYS Multiphysics, Version 14.0. ANSYS Inc., Canonsburg, Pennsylvania, USA. (www.ansys.com), 2011.

[13] ANSYS user's manual. SAS IP inc.;2011

[14] NIDA-9. Nonlinear Integrated Design and Analysis Software for Structures, Version 9, Department of Civil and Environmental Engineering, The Hong Kong Polytechnic University, Hong Kong, China, 2015.

[15] Prabhakaran, U., Godley, M.H.R. and Beale, R.G., "Three-dimensional Second Order Analysis of Scaffolds with Semi-rigid Connections", Welding in the World, 2006, Vol. 50, pp. 187-94. 
[16] Milojkovic, B., Beale, R.G. and Godley, M.H.R., "Determination of the Factors of Safety of Standard Scaffold Structures", In: Proceedings of International Conference Advances in Steel Structures, 2002, pp. 303-10.

[17] Godley, M.H.R. and Beale, R.G., "Sway Stiffness of Scaffold Structures", Structural Engineer, 1997, Vol. 75, pp. 4-12.

[18] Chu, A.Y.T., Chan, S.L. and Chung, K.F., "Stability of Modular Steel Scaffolding Systems-theory and Verification", In: Proceedings of International Conference Advances in Building Technology, 2002, pp. 621-8.

[19] JGJ61-2003 Technical Specification for Latticed Shells, China Architecture \& Building Press, Beijing, China, 2003. (in Chinese) 